OPEN ACCESS

Edited by:

Thomas Masterman,

Karolinska Institute (KI),

Sweden

Reviewed by:

Michelle Tye,

University of New South Wales,

Australia

Georgia Kalemi,

University General Hospital Attikon,

Greece

*Correspondence

Jiansong Zhou

zhoujs2003@csu.edu.cn

Xiaoping Wang

xiaop6@csu.edu.cn

Specialty section:

This article was submitted to

Forensic Psychiatry,

a section of the journal

Frontiers in Psychiatry

Received: 05 March 2019

Accepted: 20 May 2019

Published: 06 June 2019

Citation:

Zhong S, Zhu X, Mellsop G, Guo H,

Chen Y, Luo C, Li Q, Zhou J and

Wang X (2019) Mental Health

Problems, History of Drug Use, and

Violent Offending Are Associated

With Increased Suicide Risk

in Imprisoned Females.

Front. Psychiatry 10:395.

doi: 10.3389/fpsyt.2019.00395

\section{Mental Health Problems, History of Drug Use, and Violent Offending Are Associated With Increased Suicide Risk in Imprisoned Females}

\author{
Shaoling Zhong ${ }^{1}$, Xiaomin Zhu 1,2, Graham Mellsop ${ }^{3}$, Huijuan Guo ${ }^{1}$, Yanan Chen', \\ Chenyuli Luo ${ }^{1}$, Qiguang $\mathrm{Li}^{1}$, Jiansong Zhou ${ }^{1 *}$ and Xiaoping Wang ${ }^{1 *}$
}

${ }^{1}$ Department of Psychiatry of the Second Xiangya Hospital, Mental Health Institute of Central South University, China National Clinical Research Center on Mental Disorders (Xiangya), China National Technology Institute on Mental Disorders, Hunan Key Laboratory of Psychiatry and Mental Health, Changsha, China, ${ }^{2}$ Suzhou Mental Health Center, Suzhou Guangji Hospital, the Affiliated Guangji Hospital of Soochow University, Suzhou, China, ${ }^{3}$ Waikato Clinical Campus, University of Auckland, Auckland, New Zealand

Background: In western countries, imprisoned females are at high risk for suicide, but the risk in Chinese imprisoned females has not been well established. The aim of this study was to clarify the suicide risk and its correlates among imprisoned females in China.

Methods: In this cross-sectional study, subjects were recruited from the Female Prison of Hunan province, China. A standardized questionnaire was used to collect sociodemographic and criminological data. The Suicidality module of the Mini International Neuropsychiatric Interview (MINI) 5.0 and 12-item General Health Questionnaire (GHQ12) were used to assess suicide risk and mental health problems, respectively. Ordinal logistic regressions were used to identify independent factors associated with increased suicide risk.

Results: A total of 2,709 imprisoned females completed the survey questionnaire. Twenty percent were rated as presenting suicide risk. Mental health problems [odds ratio $(O R)=$ 1.21, 95\% confidence interval $(\mathrm{Cl})=1.00-1.47]$, self-reported help-seeking for mental health problems $(\mathrm{OR}=1.69,95 \% \mathrm{Cl}=1.11-2.56)$, violent offending $(\mathrm{OR}=1.69,95 \% \mathrm{Cl}=$ 1.37-2.09), history of drug use $(\mathrm{OR}=1.46,95 \% \mathrm{Cl}=1.15-1.84)$, family history of mental disorders $(\mathrm{OR}=1.57,95 \% \mathrm{Cl}=1.10-2.23)$, marital status $(\mathrm{OR}=1.29,95 \% \mathrm{Cl}=1.05$ 1.58), and low educational level $(\mathrm{OR}=1.36,95 \% \mathrm{Cl}=1.11-1.67)$ were independently associated with increased suicide risk.

Conclusion: One fifth of the imprisoned females are at risk for suicide. This study highlights the importance of assessing mental health status for suicide prevention among female prisoners.

Keywords: suicide, female, prison, mental health, ridit analysis 


\section{INTRODUCTION}

Worldwide, more than 10 million people are detained in prison (1). Imprisoned females generally account for approximately $7 \%$ of the total imprisoned population, and that figure is growing (2). The King's International Centre for Prison Studies (ICPS) (www. prisonstudies.org) reported that the number of imprisoned females had reached 700,000 all over the world in 2015. In China, the total number of imprisoned females had increased by $38.8 \%$ over one decade (from 77,279 in 2005 to 107,237 in 2015), a growth rate about nine times that of males.

Existing evidence showed an increased suicide risk in prison settings, especially for female prisoners $(3,4)$. Compared with the general population, the suicide risk is increased ranged from 6- to 20 -fold in female prisoners in western countries $(3,5)$. A recent meta-analysis including 24 high-income countries showed the suicide risk among females is around nine times than in the general population (6). Beyond these countries, little evidence represented suicide risk in low-income and middle-income countries, particularly in China. Previously effective assessment, management, and intervention to prevent suicides are important activities for policymakers, health services, and clinicians (7). In September 2018, the National Institute for Health and Care Excellence (NICE) released guidelines for suicide prevention in detention settings (8).

A number of dynamic risk factors have been identified that lead to elevated suicide risk in incarcerated settings. These include mental health needs (9) and mental health problems (10-13) or psychiatric morbidity, e.g., major depression $(14,15)$. Besides the high rate of mental health problems (16), the prison environment itself may also make females vulnerable to suicide. These modifiable risk factors would provide opportunities for further attention and intervention.

Similar to the general population $(17,18)$, there is evidence demonstrating that a quantity of fixed distal factors, including alcohol/drug misuse $(19,20)$ and early-life adversity $(21)$, are well-established correlates for increased suicide risk. A family history of mental diseases, crime, and drug/alcohol misuse might also elevate the suicide risk by contributing to adverse childhood experiences (22). Although these suicide risk factors are far less useful in predicting individual's risk, they might be beneficial in identifying high-risk groups (23).

Assessing suicide risk and providing relevant interventions are potentially cost-effective approaches to reducing suicides. Identified suicide risks appear to be sensitive predictors of actual suicide (24). Stratifying levels of suicide risk may facilitate the identification of relevant assessment, management, and intervention activities to improve outcomes in prison settings with limited mental healthcare service resources. The point has been made that the suicide risk factors in imprisoned females in China are poorly understood (25) as the available studies have been conducted in Western countries (14); therefore, we conducted this study to investigate suicide risk and related factors among imprisoned females in China. We hypothesize that certain socio-demographic, criminal, and mental health correlates are related to elevated suicide risks among imprisoned females.

\section{METHODS}

\section{Sample and Study Site}

Subjects of this cross-sectional study were recruited from the only female prison in the Hunan province which covers nearly 70 million people in central-south China. The eligible criteria for the women were as follows: 1) Chinese nationality, 2) able to communicate with and comprehend the purpose of the survey, and 3) fluent in the Chinese language. The excluding criteria were as follows: 1) with severe physical illness and 2) refusal to participate. Participants who could not read or write but were willing to join completed the study with the help of an investigator. All participants were told that they were free to quit without any punishment. No reimbursement for participation was guaranteed. Anonymity and confidentiality were guaranteed prior to the study as well. Of the total 2,916 imprisoned females, 207 were not willing or not able to participate in the study (see Figure 1), leaving a total sample of 2,709 (92.9\%). The study protocol was approved by the Clinical Research Ethics Committee of the Second Xiangya Hospital, Central South University, the authority of the Hunan Female Prison and the Bureau of Prisons in Hunan Province.

\section{Assessment Instruments}

A purpose-designed form was used to collect socio-demographic and criminological data. The socio-demographics included age, education levels, marital status, residence, personal monthly income, employment prior to prison, smoking history, history of drug use, family history of mental disorders, family history of criminal crimes and family history of alcohol/drug use, seeking help for mental health problems, and previous hospitalization due to mental health problems. The history of drug use was assessed using a dichotomous item: "in your lifetime, have you ever used any of the following drugs more than once to get high, feel better, or to change your mood" (The MINI-International Neuropsychiatric Interview, M.I.N.I). The criminological factors including criminal history (including violent history), current violent offending, imprisonment duration, and sentence. The criminal history (including violent history) was administrated using a dichotomous item: Have you ever been convicted of a crime before. For those who answered "yes," the type of crimes (homicide/assault/robbery/ defraud/prostitution/drug trafficking etc.) was confirmed. A violent history was defined as homicide, assault, robbery, and arson. The crime history was further verified by the police records.

The 12-item General Health Questionnaire (26) (GHQ-12) was administrated to measure the mental health problems. It has been used in different settings, including prison $(27,28)$. The dichotomous scale ( 0 , not at all, or same as usual; 1 , rather more or much more than usual) of GHQ-12 items was used to assess whether participants have each symptom during the last 4 weeks. A threshold of 4 and above was used to indicate the presence of mental health problems (29). This tool has been introduced and validated in China previously with good reliability and validity (30). 


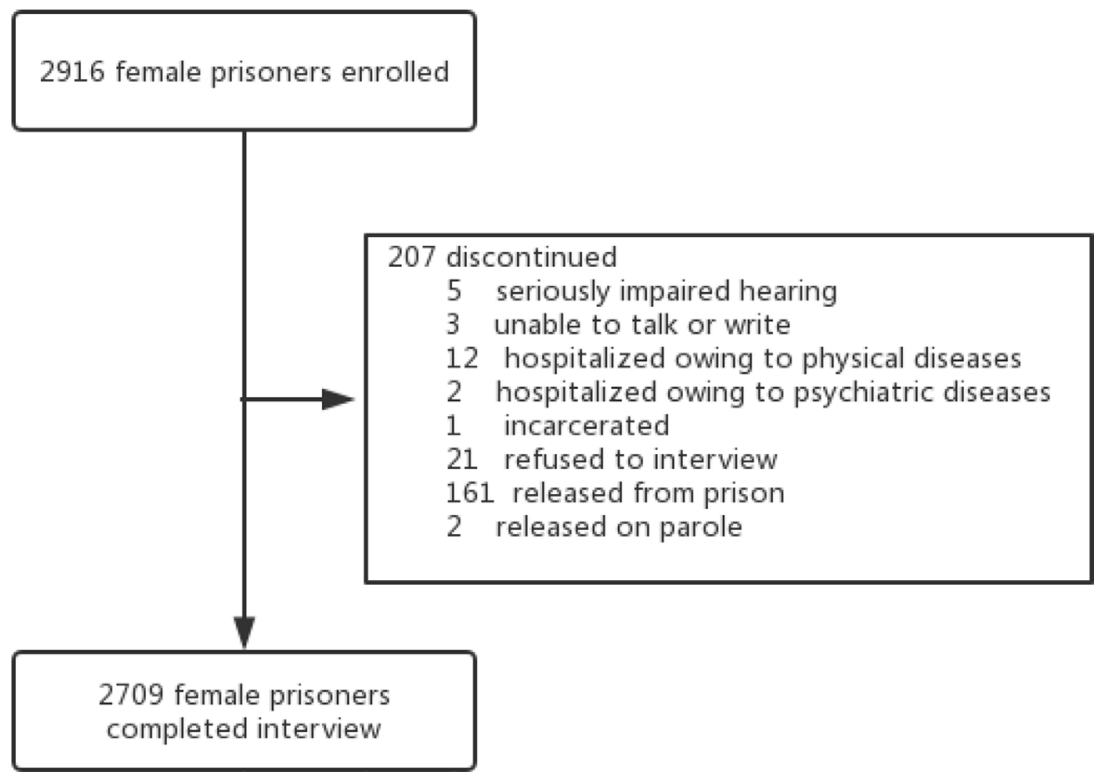

FIGURE 1 | A sampling flow chart.

The MINI-International Neuropsychiatric Interview (M.I.N.I), which is a short, structured interview tool for screening and diagnosing according to Diagnostic and Statistical Manual of Mental Disorders, Fouth Edition (DSM-IV) axis I, and 10th revision of the International Statistical Classification of Diseases and Related Health Problems (ICD-10), developed by Lecrubier and Sheehan (31), were administered to all participants. The Chinese version of M.I.N.I. was introduced by Mental Health center of Beijing University in 2006, with established reliability and validity $(32,33)$. Suicidality, the subscale of the M.I.N.I. 5.0, was administrated to assess suicide risk. There are six items in the tool as listed in Table 1. The points for the six items were added to get a total point score. In this study, four suicide risk levels were used: non-suicidal risk, lowsuicidal risk, moderate-suicidal risk, and high-suicidal risk.

\section{Procedures}

Prior to the initiation of the survey, an advertisement about the purpose was distributed by the prison officers to all imprisoned females. After giving written informed consent, participants were asked to complete the standardized questionnaire with the assistance of our trained investigators (when necessary). Before collection of the questionnaire, our investigators checked the questionnaire to avoid missing data. After completing the questionnaire, participants were interviewed face-toface individually in a quiet room at the prison by a trained psychiatrists, using the suicidality module of the M.I.N.I.

\section{Statistical Analyses}

The IBM Statistic Package for Social Sciences (SPSS) version 18.0 was used for all statistical analyses. Categorical variables were presented as numbers and percentages, and continuous variables were presented as mean \pm standard deviation (SD). To compare socio-demographic, criminological, and mental health factors across different suicidal risk groups, one-way analysis of variance (ANOVA) was used for continuous variables (i.e., age). Then, as the outcome is termed ordinal (non-/low-/moderate-/highsuicide risks), the Ridit analyses were adopted for all the other variables. The Ridit analyses, which consider the ordering of categories, were developed by Bross (34) and widely used in health care areas. Finally, the ordinal logistic regressions were performed

TABLE 1 | Items of suicidality in the MINI-International Neuropsychiatric Interview (M.I.N.I.).

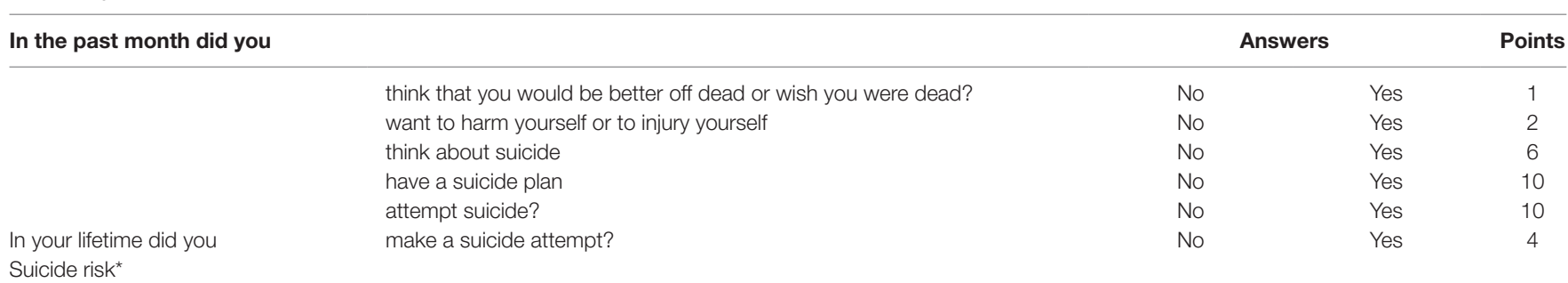

${ }^{*}$ The points for the six items are added to get a total point. The total point of 0 is ranked as non-risk, between 1-5 is ranked as low risk, 6-10 as moderate risk, and $>10$ as high risk. 
to evaluate factors associated with increased or decreased suicide risks. Variables that were statistically significant on univariate analysis were entered into ordinal logistic regression. Two-tailed $p$ values of 0.05 were set as statistically significant.

\section{RESULTS}

\section{Socio-Demographics, Criminological Characteristics, and Suicide Risk}

The mean age of the 2,709 imprisoned females was 39.8 (SD = 10.4) years, ranging from 15 to 81 years. In the imprisoned females, $56.8 \%$ were married, $36.9 \%$ had received less than 6 years of education, $43.0 \%$ were unemployed prior to prison, and $6.8 \%$ had a criminal history.

A total of $548(20.2 \%)$ reported apparent recent suicidal risk: 456 (16.8\%) low, 78 (2.8\%) moderate, and 14 (0.5\%) high. The sociodemographic and criminological variables for the different suicidal risk groups are shown in Table 2 . There are significant differences in age $(F=26.19, p<0.01)$, education levels $(F=2.82, p=0.04)$, employment $(F=5.09, p=0.02)$ and marital status $(F=13.61, p<$ $0.01)$. Furthermore, violent offending $(F=25.81, p<0.01)$, history of drug use $(F=8.68, p<0.01)$, and family history of mental disorders $(F=12.21, p<0.01)$ differed significantly between the four groups.

\section{Comparison of Mental Health Status Between the Different Suicidal Risk Groups}

Table 2 also shows the mental health status among the four groups. A total of 991 (36.6\%) imprisoned females reported the presence of mental health problems. One hundred twentyseven $(4.7 \%)$ of them had ever sought help for their mental health problems, with only $28.3 \%(36 / 127)$ having experienced hospitalization. The presence of mental health problems $(F=$ 5.36, $p=0.02)$, seeking help for mental health problems $(F=$ $12.96, p<0.01$ ), and hospitalization history due to mental health problems $(F=6.11, p=0.01)$ were all significantly related to increased suicidal risk.

\section{Correlates of Suicide Risk}

As shown in Table 3, several factors were significantly associated with increased suicide risk. These factors were violent offending [odds ratio $(\mathrm{OR})=1.69,95 \%$ confidence interval $(\mathrm{CI})=1.37-$ 2.09], history of drug use $(\mathrm{OR}=1.46,95 \% \mathrm{CI}=1.15-1.84)$, family history of mental disorders (OR $=1.57,95 \% \mathrm{CI}=1.10-$ $2.56)$, seeking help for mental health problems ( $\mathrm{OR}=1.69,95 \%$ $\mathrm{CI}=1.11-2.56)$, married status $(\mathrm{OR}=1.29,95 \% \mathrm{CI}=1.05-$ $1.58)$ and low education level $(\mathrm{OR}=1.36,95 \% \mathrm{CI}=1.11-1.67)$.

\section{DISCUSSION}

To our knowledge, this is the first study to examine suicide risk and its socio-demographic, criminal, and mental health correlates among imprisoned females in China. This study revealed that one fifth of imprisoned females demonstrated recent suicide risk. Mental health problems, seeking help for mental health problems prior to the prison, family history of mental disorders, history of drug use, violent offending, being married, and a lower education level were associated with increased suicide risk. These findings provide clinically relevant information for identifying high-risk individuals and underpin the importance of screening for mental health problems and providing adequate psychiatric care in female prison.

The $20.2 \%$ prevalence of suicide risk in Chinese imprisoned females is comparable with the rate demonstrated in imprisoned females of French Guiana (20.0\%) (35). Among the general population, female gender per se is an independent risk factor of suicidality (36). The complex, unmet female-sensitive needs in prisons might explain the high suicide risk in imprisoned females (37).

As described in western countries $(10,12)$, mental health problems are significantly associated with increased suicide risk. As mental health service is important for suicide prevention (18, 38), identifying and treating persons with mental health problems should be considered a routine component of mental health service. Earlier studies have found that the presence of family history of mental disorders is independently associated with increased suicide risk both in the community $(39,40)$ and prison settings (41), which we confirm. In addition to standard screening tools, our findings supported that self-reported help-seeking for mental health problems prior to the imprisonment is another correlate of suicide risk. This probably reflects that a number of imprisoned females with suicide risk may have been treated for their mental health problems prior to going in to prison (42). This finding is partly consistent with the NICE guideline, which emphasizes the importance of assessing mental health status and help-seeking behaviors in detention settings to identify people at high risk. Therefore, one implication for these is to screen for mental health problems and history of seeking help for mental health problems. It would also follow that it is likely to be helpful to reduce suicide risk to encourage help-seeking behaviors in the prison and to provide useful information on how and where to seek help.

High prevalence of drug use has been consistently reported in prison populations. This has been shown to be particularly the case for females $(19,43)$. A systematic review $(43)$ reported that the prevalence of drug abuse or dependence varied from $30 \%$ to $60 \%$ in imprisoned females in western countries. The prevalence of drug use (15.9\%) in our study is substantially lower than those figures, which could be ascribed to cultural and legal system differences between China and western countries. History of drug use has been frequently reported to be associated with both suicide risk and completed suicides $(44,45)$ in prison population. In line with these findings, drug use was associated with elevated suicide risk in this study. This relationship could be due to the withdrawal symptoms (both acute and prolonged) of these drug abusers, including depression, anxiety, and pain. Another possible explanation for this is that impulsiveness might work as a mediation between drug use and suicide risk. Earlier studies found that prison inmates with a lifetime history of drug use and suicide risk often have higher impulsiveness (46-48). Further pathway studies looking specifically at impulsiveness could improve understanding relationships between drug use and suicide risk. The robust relation between drug use and suicide risk suggest the 


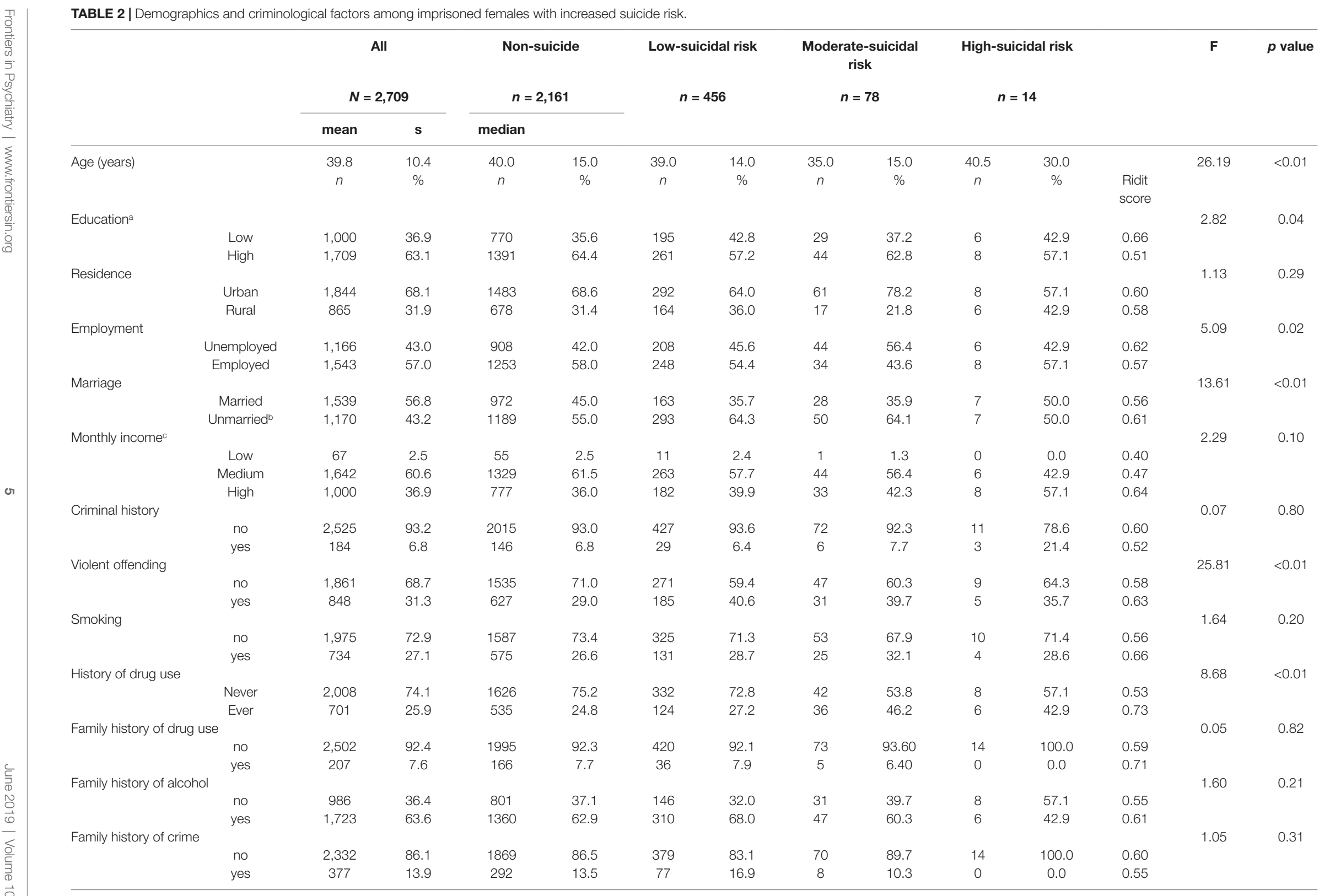


TABLE 2 | Continued

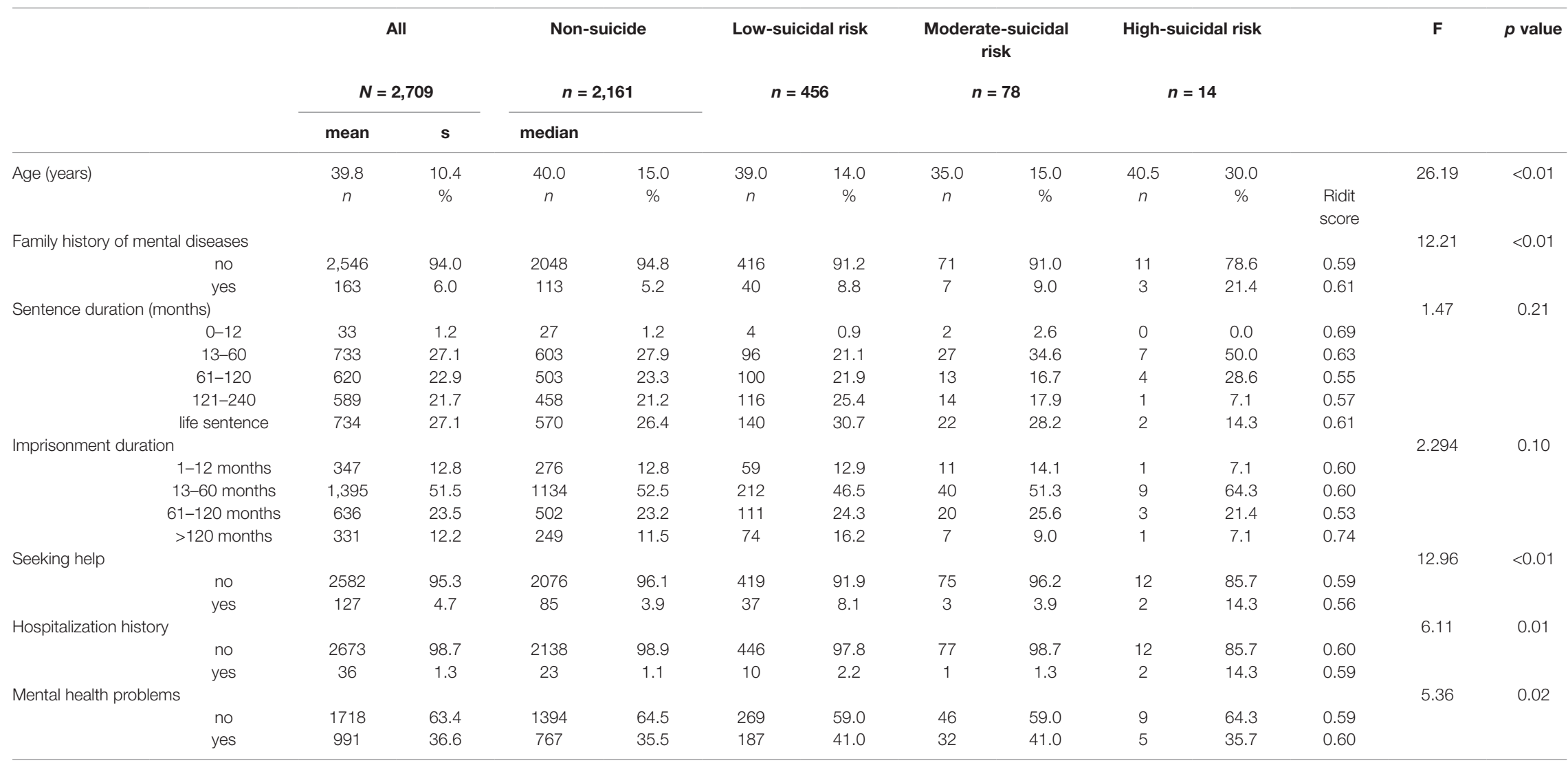

aEducation level $\leq 6$ years was defined as low, education level $>6$ years was defined as high.

bUnmarried includes single, divorced, and widow.

cMonthly Income $\leq$ poverty threshold ( $¥ 2,300$ per person per year in 2013 in China) was defined as low, poverty threshold <monthly income $\leq$ per capita disposable income ( $¥ 23,414$ per person per year in 2013 in Hunan) was defined as medium, monthly income > per capital disposable income was defined as high. 
TABLE 3 | Ordinal logistic regression model assessing variables associated with increased suicide risk.

\begin{tabular}{|c|c|c|c|c|c|}
\hline \multirow[t]{2}{*}{ Variables } & & \multirow[t]{2}{*}{ OR } & \multicolumn{2}{|c|}{$95 \% \mathrm{Cl}$} & \multirow[t]{2}{*}{$p$ value } \\
\hline & & & Lower & Upper & \\
\hline Age & & 0.99 & 0.98 & 1.00 & 0.02 \\
\hline \multirow[t]{2}{*}{ Marital status } & Married & 1.29 & 1.05 & 1.58 & 0.02 \\
\hline & Unmarrieda & 1.00 & & & \\
\hline Unemployment & & 1.12 & 0.91 & 1.37 & 0.29 \\
\hline \multirow[t]{2}{*}{ Education $^{b}$} & Low & 1.36 & 1.11 & 1.67 & $<0.01$ \\
\hline & High & 1.00 & & & \\
\hline Violent offending & & 1.69 & 1.37 & 2.09 & $<0.01$ \\
\hline History of drug use & & 1.46 & 1.15 & 1.84 & $<0.01$ \\
\hline Family history of mental disorders & & 1.57 & 1.10 & 2.23 & 0.01 \\
\hline Seeking help & & 1.69 & 1.11 & 2.56 & 0.01 \\
\hline Hospitalization history & & 1.53 & 0.73 & 3.21 & 0.26 \\
\hline Mental health problems & & 1.21 & 1.00 & 1.47 & 0.05 \\
\hline
\end{tabular}

OR, odds ratio; 95\% Cl, 95\% confidence interval.

aUnmarried status includes single, divorced and widow.

${ }^{b}$ Education level $\leq 6$ years was defined as low; education level $>6$ years was defined as high.

importance of targeting those imprisoned females with history of drug use for further evaluation and management to reduce their risk of suicide.

A strong correlation between criminal characteristics and suicide risk has been previously reported in a systematic review (10). Imprisoned females charged with violent offending demonstrated elevated suicide risk in our study, replicating findings in other countries $(42,44,45,49)$. This may be contributed to by to shame, guilt, and stigma associated with violent offending. Previous researchers have suggested sentence duration is associated with increased suicide risk $(36,50)$, in particular lifetime sentences (10). In this study, no such association was found. Further studies about specific offense type and sentence duration are necessary to clarify these apparent discrepancies. Given the criminological influences in imprisoned females, additional attention and interventions for those with certain criminal characteristics should also be given priority.

\section{IMPLICATIONS}

There are two main implications. First, the reported prevalence of suicide risk underlines the need to assess suicide risk among incarcerated females, despite the $3 \%$ of them having a moderateto-high suicide risk. The second implication is that the findings support the hypothesis that suicide risks in incarcerated females are relevant to detective correlators. Although these risk factors might not be effective to predict suicide, they could be identified to assess suicide risk for the stakeholders. In practice, the presence of low suicide risk would need a dynamic assessment, while those with high suicide risk could lead to a further clinical examination by mental health professionals.

\section{LIMITATIONS}

Some limitations should be clarified. First, the retrospective and cross-sectional study designs have the inability to draw a causal or pathogenic relationship between identified correlates and increased suicide risk. So, whether these factors result in an increase in suicide risk needs to be verified in prospective studies. Also, the self-report nature of the data could also add potential bias due to sensitivity and stigma of suicide (51). Second, suicide risk of imprisoned females might be underestimated, because this study was conducted in prison, and participants may conceal or deny their real intention to die. Third, due to limited interview time, this study did not collect data on other potentially important risk factors of suicide, such as childhood trauma (52).

\section{CONCLUSION}

In conclusion, suicidal risk in $20.2 \%$ of imprisoned females was measured in China. Independent associated factors included mental health problems, family history of mental disorders, history of drug use, violent offending, marital status, and education level. These findings may facilitate targeting management, effective intervention with limited sources, and contribution to prevention. Further longitudinal follow-up would help determine the value of these factors in predicting suicide and in informing the development of preventive strategies.

\section{DATA AVAILABILITY STATEMENT}

The datasets generated for this study are available on request to the corresponding author.

\section{ETHICS STATEMENT}

The study protocol was approved by the Clinical Research Ethics Committee of the Second Xiangya Hospital, Central South University, the authority of the Hunan Female Prison and the Bureau of Prisons in Hunan Province. 


\section{AUTHOR CONTRIBUTIONS}

All authors have been involved in the preparation and completion of the study. They have also read and approved this report.

\section{FUNDING}

This work was supported and funded by the National Key Research and Development Program of China (2016YFC0800701), National Natural Science Foundation of China [grant number: 81571341], [grant 81371500], National Key Research and Development Program of Hunan province [grant: 2018SK2133]

\section{REFERENCES}

1. Walmsley R. World Prison Population List. 8th edn. London: Kings College and International Centre for Prison Studies (2009).

2. Chesney-Lind M, Pasko L. The female offender: girls, women, and crime. California, United States: Sage (2013). doi: 10.4135/9781483387567

3. Fazel S, Grann M, Kling B, Hawton K. Prison suicide in 12 countries: an ecological study of 861 suicides during 2003-2007. Soc Psychiatry Psychiatr Epidemiol (2011) 46(3):191-5. doi: 10.1007/s00127-010-0184-4

4. World Health Organization. Women's health in prisons: correcting gender inequity in prison health. (2009).

5. Fazel S, Benning R. Suicides in female prisoners in England and Wales, 1978 2004. Br J Psychiatry (2009) 194(2):183-4. doi: 10.1192/bjp.bp.107.046490

6. Fazel S, Ramesh T, Hawton K. Suicide in prisons: an international study of prevalence and contributory factors. Lancet Psychiatr (2017) 4(12):946-52. doi: 10.1016/S2215-0366(17)30430-3

7. Forrester A, Slade K. Preventing self-harm and suicide in prisoners: job half done. Lancet (2014) 7:1109-11. doi: 10.1016/S0140-6736(13)62571-4

8. The Lancet. Suicide in prisons: NICE fights fires. 1474-547X Contract No.: 10124. Lancet (2018) 391:912. doi: 10.1016/S0140-6736(18)30554-3

9. Pratt D, Appleby L, Piper M, Webb R, Shaw J. Suicide in recently released prisoners: a case-control study. Psychol Med (2010) 40(5):827-35. doi: 10.1017/S0033291709991048

10. Fazel S, Cartwright J, Normannott A, Hawton K. Suicide in prisoners: a systematic review of risk factors. J Clin Psychiatr (2008) 69(11):1721-31. doi: 10.4088/JCP.v69n1107

11. Hurley W, Dunne MP. Psychological distress and psychiatric morbidity in women prisoners. ANJZP (1991) 25(4):461-70. doi: 10.3109/ 00048679109064439

12. Fazel S, Hayes AJ, Bartellas K, Clerici M, Trestman R. Mental health of prisoners: prevalence, adverse outcomes, and interventions. Lancet Psychiatr (2016) 3(9):871-81. doi: 10.1016/S2215-0366(16)30142-0

13. Hawton K, Casanas ICC, Haw C, Saunders K. Risk factors for suicide in individuals with depression: a systematic review. J Affect Disord (2013) 147(1-3):17-28. doi: 10.1016/j.jad.2013.01.004

14. Fazel S, Seewald K. Severe mental illness in 33,588 prisoners worldwide: systematic review and meta-regression analysis. Br J Psychiatry (2012) 200(5):364-73. doi: 10.1192/bjp.bp.111.096370

15. Chapman AL, Specht MW, Cellucci T. Factors associated with suicide attempts in female inmates: the hegemony of hopelessness. Suicide LifeThreat Behav (2005) 35(5):558-69. doi: 10.1521/suli.2005.35.5.558

16. Diamond PM, Wang EW, Holzer CE, Thomas C. The prevalence of mental illness in prison. Adm Policy in Mental Health Mental Health Serv Res (2001) 29(1):21-40. doi: 10.1023/A:1013164814732

17. Hawton K, van Heeringen K. Suicide. Lancet (London, Eng) (2009) 373(9672), 1372-81. doi: 10.1016/S0140-6736(09)60372-X

18. Turecki G, Brent DA. Suicide and suicidal behaviour. Lancet (London, England) (2016) 387(10024):1227-39. doi: 10.1016/S0140-6736(15)00234-2

19. Binswanger IA, Merrill JO, Krueger PM, White MC, Booth RE, Elmore JG. Gender differences in chronic medical, psychiatric, and and Natural Science Foundation of Hunan, China [grant: 2019SK0511]. National Natural Science Foundation of China (81571316) and the Natural Science Foundation of Jiangsu Province (BK20180213).

\section{ACKNOWLEDGMENTS}

The authors would like to thank all prison policemen in Hunan provincial Female Prison who assisted in this study and all the prisoners who took part in it. The authors would also like to thank Ziwei Liu, for his valuable suggestions about the statistical analysis.

substance-dependence disorders among jail inmates. Am J Pub Health (2010) 100(3):476-82. doi: 10.2105/AJPH.2008.149591

20. Tripodi SJ, Onifade E, Pettus-Davis C. Nonfatal suicidal behavior among women prisoners: the predictive roles of childhood victimization, childhood neglect, and childhood positive support. Intl J Offender Ther Comp Criminol (2014) 58(4):394-411. doi: 10.1177/0306624X12472879

21. Chen G, Gueta K. Lifetime history of suicidal ideation and attempts among incarcerated women in israel. Psychol Trauma (2017) 9(5):596. doi: 10.1037/ tra0000277

22. De Ravello L, Abeita J, Brown P. Breaking the cycle/mending the hoop: adverse childhood experiences among incarcerated American Indian/Alaska Native women in New Mexico. Health Care Women Intl (2008) 29(3):300-15. doi: 10.1080/07399330701738366

23. Hawton K. Assessment of suicide risk. Br J Psychiatr (1987) 150(2):145-53. doi: 10.1192/bjp.150.2.145

24. Coryell W, Young EA. Clinical predictors of suicide in primary major depressive disorder. J Clin Psychiatr (2005) 66:412-7. doi: 10.4088/JCP.v66n0401

25. Gould C, McGeorge T, Slade K. Suicide screening tools for use in incarcerated offenders: a systematic review. Arch Suicide Res (2018) 22(3):345-64. doi: 10.1080/13811118.2017.1334611

26. Goldberg DP. User's guide to the General Health Questionnaire. Windsor (1988).

27. Smith C, Borland J. Minor psychiatric disturbance in women serving a prison sentence: the use of the General Health Questionnaire in the estimation of the prevalence of non-psychotic disturbance in women prisoners. Legal Criminol Psychol (1999) 4(2):273-84. doi: 10.1348/135532599167905

28. Hewitt CE, Perry AE, Adams B, Gilbody SM. Screening and case finding for depression in offender populations: a systematic review of diagnostic properties. J Affect Disord (2011) 128(1-2):72-82. doi: 10.1016/j.jad.2010.06.029

29. Goldberg DP, Gater R, Sartorius N, Ustun TB, Piccinelli M, Gureje O, et al. The validity of two versions of the GHQ in the WHO study of mental illness in general health care. Psychol Med (1997) 27(1):191-7. doi: 10.1017/ S0033291796004242

30. Yang T, Huang L, Wu Z. Study on the appropriateness of the Chinese version of the General Health Questionnaire as a screening instrument for psychological disorders in mainland China. Chin J Epid (2003) 24(9):769-73. doi: 10.3760/j.issn:0254-6450.2003.09.006

31. Lecrubier Y, Sheehan DV, Weiller E, Amorim P, Bonora I, Sheehan KH, et al. The Mini International Neuropsychiatric Interview (MINI). A short diagnostic structured interview: reliability and validity according to the CIDI. Euro Psychiatry (1997) 12(5):224-31. doi: 10.1016/S0924-9338(97)83296-8

32. Tian-Mei S, Liang S, Wei-Min D, Yun-Ai S, Jing-Xu C, Wen-Tian D, et al. Evaluation of the Reliability and Validity of Chinese Version of the M.I.N.I.-International Neuropsychiatric Interview in Patients with Mental Disorders. Chin Mental Health J (2009) (z1):30-6. doi: 10.3969/j. issn.1000-6729.2009.07.011

33. Zhong BL, Liu TB, Chan SSM, Jin D, Hu CY, Dai J, et al. Common mental health problems in rural-to-urban migrant workers in Shenzhen, China: prevalence and risk factors. Epidemiol Psychiatr Sci (2017) 27:256-65. doi: $10.1017 /$ s2045796016001141 
34. Bross ID. How to use ridit analysis. Biometrics (1958) 14(1):18-38. doi: $10.2307 / 2527727$

35. Ayhan G, Arnal R, Basurko C, About V, Pastre A, Pinganaud E, et al. Suicide risk among prisoners in French Guiana: prevalence and predictive factors. BMC Psychiatry (2017) 17(1):156. doi: 10.1186/s12888-017-1320-4

36. Nock MK, Borges G, Bromet EJ, Alonso J, Angermeyer M, Beautrais A, et al. Cross-national prevalence and risk factors for suicidal ideation, plans and attempts. Br J Psychiatry (2008) 192(2):98-105. doi: 10.1192/bjp.bp.107.040113

37. Bartlett A, Hollins S. Challenges and mental health needs of women in prison. Br J Psychiatry (2018) 212(3):134-6. doi: 10.1192/bjp.2017.42

38. Chen R, An J, Ou J. Suicidal behaviour among children and adolescents in China. The Lancet Child \& Adolescent Health (2018) 2(8):551-3. doi: 10.1016/S2352-4642(18)30170-6

39. Qin P, Agerbo E, Mortensen PB. Suicide risk in relation to family history of completed suicide and psychiatric disorders: a nested case-control study based on longitudinal registers. Lancet (2002) 360(9340):1126-30. doi: 10.1016/S0140-6736(02)11197-4

40. Sørensen HJ, Mortensen EL, Wang AG, Juel K, Silverton L, Mednick SA. Suicide and mental illness in parents and risk of suicide in offspring. Soc Psychiatry Psychiatric Epidemiol (2009) 44(9):748-51. doi: 10.1007/s00127-009-0495-5

41. Daniel AE. Preventing suicide in prison: a collaborative responsibility of administrative, custodial, and clinical staff. J Am Acad Psychiatry Law Online (2006) 34(2):165-75. doi: 10.1086/498836

42. Sarchiapone M, Carli V, Giannantonio MD, Roy A. Risk factors for attempting suicide in prisoners. Suicide Life Threat Behav (2009) 39(3):343-50. doi: 10.1521/suli.2009.39.3.343

43. Fazel S, Bains P, Doll H. Substance abuse and dependence in prisoners: a systematic review. Addiction (2006) 101(2):181-91. doi: 10.1111/j.13600443.2006.01316.x

44. Blaauw E, Kerkhof AJ, Hayes LM. Demographic, criminal, and psychiatric factors related to inmate suicide. Suicide Life Threat Behav (2005) 35(1):6375. doi: 10.1521/suli.35.1.63.59268

45. Way BB, Miraglia R, Sawyer DA, Beer R, Eddy J. Factors related to suicide in New York state prisons. Int J Law Psychiatry (2005) 28(3):207-21. doi: 10.1016/j.ijlp.2004.09.003
46. Bernstein MH, McSheffrey SN, van den Berg JJ, Vela JE, Stein L, Roberts $\mathrm{MB}$, et al. The association between impulsivity and alcohol/drug use among prison inmates. Addict Behav (2015) 42:140-3. doi: 10.1016/j. addbeh.2014.11.016

47. Ireland JL, Higgins P. Behavioural stimulation and sensation-seeking among prisoners: applications to substance dependency. Intl J Law Psychiatr (2013) 36(3-4):229-34. doi: 10.1016/j.ijlp.2013.04.006

48. Vadini F, Calella G, Pieri A, Ricci E, Fulcheri M, Verrocchio MC, et al. Neurocognitive impairment and suicide risk among prison inmates. J Affect Disorder (2018) 225:273-7. doi: 10.1016/j.jad.2017.08.030

49. Rabe K. Prison structure, inmate mortality and suicide risk in Europe. Int $J$ Law Psychiatry (2012) 35(3):222-30. doi: 10.1016/j.ijlp.2012.02.012

50. Hawton K, Linsell L, Adeniji T, Sariaslan A, Fazel S. Self-harm in prisons in England and Wales: an epidemiological study of prevalence, risk factors, clustering, and subsequent suicide. Lancet (London, England) (2014) 383(9923):1147-54. doi: 10.1016/S0140-6736(13)62118-2

51. Xi Y, Chen R, Yan F, Ma X, Rakofsky JJ, Tang L, et al. Low post-traumatic stress disorder rate in Chinese in Beijing, China. Asian J Psychiatry (2017) 30:79-83. doi: 10.1016/j.ajp.2017.07.003

52. Clements-Nolle K, Wolden M, Bargmann-Losche J. Childhood trauma and risk for past and future suicide attempts among women in prison. Womens Health Issues (2009) 19(3):185-92. doi: 10.1016/j.whi.2009. 02.002

Conflicts of Interest Statement: The authors declare that the research was conducted in the absence of any commercial or financial relationships that could be construed as a potential conflict of interest.

Copyright $\odot 2019$ Zhong, Zhu, Mellsop, Guo, Chen, Luo, Li, Zhou and Wang. This is an open-access article distributed under the terms of the Creative Commons Attribution License (CC BY). The use, distribution or reproduction in other forums is permitted, provided the original author(s) and the copyright owner $(s)$ are credited and that the original publication in this journal is cited, in accordance with accepted academic practice. No use, distribution or reproduction is permitted which does not comply with these terms. 